Special issue of the 2nd International Conference on Computational and Experimental Science and Engineering (ICCESEN 2015)

\title{
A Study on Radiation in Operating Room in Suleyman Demirel University
}

\author{
Ü. KARA ${ }^{a}$, Y. KARA ${ }^{b}$ AND I. AKKURT ${ }^{c, *}$ \\ ${ }^{a}$ Suleyman Demirel University, Vocational School of Healt Services, Isparta, Turkey \\ ${ }^{b}$ Suleyman Demirel University, Faculty of Medicine, Isparta, Turkey \\ ${ }^{c}$ Suleyman Demirel University, Physics Department, Isparta, Turkey
}

\begin{abstract}
Despite the use of ionizing radiation and most of the harmful effects commonly known but not shown, insufficient attention has been observed for radiation protection. Radiation-exposed patients, physicians, health care team and staff should receive training in this field. The aim of this study is the doses of radiation in the operating room to identify and inform health personnel in radiation protection. Radiation exposure to operating room staff (doctor, nurse, medical staff, X-ray technician, anaesthesia technician, etc.) has been recognized as a necessary hazard in operating room. The purpose of our work is to determine operating room staff radiation doses for operating room to identify procedures associated with higher radiation doses, and to determine the effects of various parameters on staff doses. This study was performed at Suleyman Demirel University Medical Faculty Hospital. The procedure of study was performed in department of anaesthesia. We recorded that radiation doses data include all related imaging performed as part of department procedure. The distances were 100, 150, $250 \mathrm{~cm}$ from X-ray tube. It is important to understand that radiation affects medical staff in operating procedures. Use of low doses of ionizing radiation does not have knowledge of the long-term results but we need to be careful to conclude that use of radiological protection. During radiation protection, the maximum dose, even under the thick, the minimum degree of exposure to radiation is an important factor for our health. In addition, in the study, Philips BV-25 Gold is used as a brand fluoroscopic device. Device, $1.2-2 \mathrm{kV}, 60-100 \mathrm{~mA} / \mathrm{s}$ of doses between the values.
\end{abstract}

DOI: 10.12693/APhysPolA.130.401

PACS/topics: 87.56.-v, 87.55.Qr

\section{Introduction}

Medicine usage in neurological, oncological, orthopedic, kidney, heart, and lung applications can be classified as applications of radiation. Approximately $4-10$ million interventional pain procedures are performed annually in the United States, with at least $50 \%$ of them being performed under fluoroscopy [1-7]. Diagnostic radiological examinations is difficult to measure doses of physicians and their patients. Outside of the known effects of radiation, the effects of surgical operations are still largely unknown due to use of it. Working in the operating room as a technicians, nurses and staff do not know the amount of radiation and radiation protection rules, personnel does not know radiation hazard. During these operations personnels take directly the dose in the form of light scattering or leakage from the radiation. It has been reported that physicians performing the radiographic or fluoroscopic procedures in the first half of the 20th century had higher rates of cancer-related deaths than any other physicians [3]. Leakage ray sometimes comes from fluoroscopy device and to avoid this, the devices used and the test should be calibrated periodically. Reflection occurs when the patient's body came in the ray or in the objects. The surgical procedure in the operating room, according to shortness or length taken radiation doses, is different. Injuries to skin, muscle, and eye lens

${ }^{*}$ corresponding author; e-mail: umitkara@sdu.edu.tr due to the radiation from fluoroscopic procedures have been widely documented [8-10]. In this study, we measured fluoroscopy unit in our university department of anaesthesia clinics to evaluate the mean fluoroscopy time and total radiation exposure for various treatment management procedures. The aim of this study is appropriateness of fluoroscopy use in university medical faculty hospital for the purpose of designing a better shielding operating room.

\section{Material and method}

In the Suleyman Demirel Research Hospital, the C-arm fluoroscopy was a Philips BV-25 Gold with $40-100 \mathrm{kV}$ and the automatic brightness control (ABC) was used at around $3 \mathrm{~mA}$ (Table I). We repeated the measurements for one month and worked with Polimaster PM-1621 $\mathrm{X}$-ray and gamma ray radiation personal dosimeter in

TABLE I

The use of fluoroscopy.

\begin{tabular}{c|c}
\hline \hline \multicolumn{2}{c}{ Philips, BV-25 Gold } \\
\hline $220 \mathrm{VAC}$ & $20 \mathrm{~mA} 100 \mathrm{kVp}$ \\
heat capacity, hu (X-ray tube) & 25000 \\
cooling, hu/min (max output) & 12000 \\
power requirements & $120 / 220 \mathrm{VAC}, 30 / 16 \mathrm{~A}$ \\
$\mathrm{kV}$ range (X-ray generator) & 40 \\
$\mathrm{~mA}$ range (imaging system) & 20 \\
$\mathrm{kV}$ range (X-ray generator) & 40 \\
image matrix size & $480 \times 1400 \times 10$
\end{tabular}


Features of personal dosimeter PM-1621.

\begin{tabular}{|c|c|}
\hline Detector & GM tube \\
\hline DER measurement range & $0.1 \mu \mathrm{Sv} / \mathrm{h}-100 \mathrm{mSv} / \mathrm{h}$ \\
\hline Dose rate accuracy & $\begin{array}{c} \pm(15+0.0015 / \mathrm{H}+0.01 \mathrm{H}) \% \\
(\text { in range } 0.1 \mu \mathrm{Sv} / \mathrm{h}-0.1 \mathrm{~Sv} / \mathrm{h}, \\
\mathrm{H}-\text { dose rate in } \mathrm{mSv} / \mathrm{h})\end{array}$ \\
\hline DE measurement range & $\begin{array}{c}0.01 \mu \mathrm{Sv}-9.99 \mathrm{~Sv} \\
(1 \mu \mathrm{R}-999 \mathrm{R})\end{array}$ \\
\hline Dose accuracy & $\begin{array}{c} \pm 15 \% \text { (in range } 1 \mu \mathrm{Sv}-9.99 \mathrm{~Sv} \\
(100 \mu \mathrm{R}-999 \mathrm{R})) \\
\end{array}$ \\
\hline Energy range & $10.0 \mathrm{KeV}-20.0 \mathrm{MeV}$ \\
\hline $\begin{array}{c}\text { Energy response relative } \\
\text { to } 0.662 \mathrm{MeV}\left({ }^{137} \mathrm{Cs}\right)\end{array}$ & $\pm 30 \%$ \\
\hline $\begin{array}{c}\text { Survive after momentary influence } \\
\text { of maximum permissible gamma } \\
\text { radiation within } 5 \mathrm{~min}\end{array}$ & $\begin{array}{c}1 \mathrm{~Sv} / \mathrm{h} \\
(100 \mathrm{R} / \mathrm{h})\end{array}$ \\
\hline
\end{tabular}

interventional radiology (Table II). The operator was generally a fellow and the assistant was a resident. Before the procedures started, the operator, the assistant and we were led apron. For procedural convenience, the operator stood ordinary to the patient, and we stood 100 , 150, $250 \mathrm{~cm}$ away (Fig. 1). After the study period, the radiation exposure rates of the dosimeters were evaluated by our radiation safety unit of our hospital.

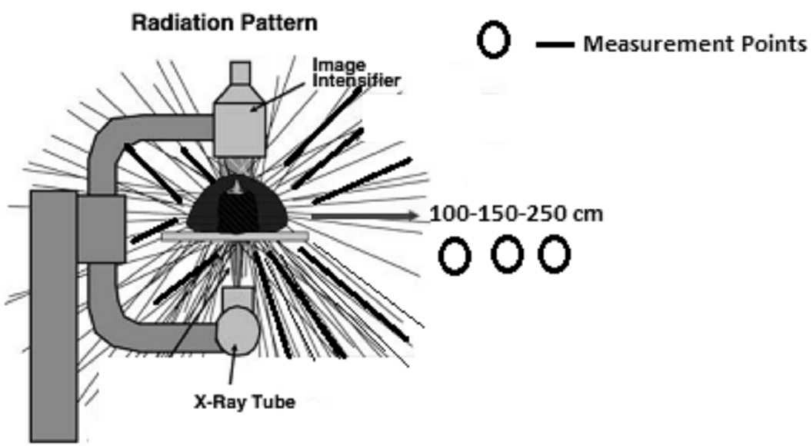

Fig. 1. Fluoroscopy unit area measurement distance.

\section{Results}

During this process, of the operating table $100 \mathrm{~cm}$, $150 \mathrm{~cm}$ one of $250 \mathrm{~cm}$ away from the operating table and two types of measurement devices used for the measurements were taken. Fluoroscopy images were obtained with the help of joystick handle. During this period, during operations in surgery, urology, orthopedics, and traumatology, and shots were averaged and the average dose values were given in the tables. The level of exposure is inversely related to the square of the distance. Thus, if the distance doubles, the radiation exposure level drops 4 times [3]. In general, the scattered radiation level from the patients when standing $1 \mathrm{~m}$ apart is only about $0.1 \%$ of the patient's absorbed dose rate $[6]$.
The use of fluoroscopy and radiation doses.

\begin{tabular}{c|c|c|c|c|c}
\hline \hline $\begin{array}{c}100 \mathrm{~cm} \\
{[\mathrm{mR} / \mathrm{h}]}\end{array}$ & $\begin{array}{c}100 \mathrm{~cm} \\
{[\mu \mathrm{Sv} / \mathrm{h}]}\end{array}$ & $\begin{array}{c}150 \mathrm{~cm} \\
{[\mathrm{mR} / \mathrm{h}]}\end{array}$ & $\begin{array}{c}150 \mathrm{~cm} \\
{[\mu \mathrm{Sv} / \mathrm{h}]}\end{array}$ & $\begin{array}{c}250 \mathrm{~cm} \\
{[\mathrm{mR} / \mathrm{h}]}\end{array}$ & $\begin{array}{c}250 \mathrm{~cm} \\
{[\mu \mathrm{Sv} / \mathrm{h}]}\end{array}$ \\
\hline \multicolumn{6}{c}{ percutaneous nephrolithotomy $(\mathrm{PNL})$} \\
\hline 3 & 6.5 & 2.5 & 4.5 & 1 & 3 \\
4 & 7.2 & 3 & 6 & 2.5 & 3.5 \\
5.3 & 13.2 & 3.5 & 10 & 3 & 6 \\
13.6 & 26 & 8.5 & 18 & 5 & 10 \\
14.5 & 28 & 10.5 & 22 & 8 & 15 \\
\hline \multicolumn{6}{c}{ lumbar disc herniation (LDH) } \\
\hline 5.5 & 16.3 & 4 & 12.3 & 3 & 3.45 \\
9.2 & 20.1 & 7.5 & 18.3 & 3.2 & 4.12 \\
12 & 30.5 & 10 & 20.5 & 4 & 4.54 \\
13.5 & 56.4 & 11.5 & 29 & 4.6 & 5.6 \\
14.2 & 57.6 & 13 & 50.5 & 5 & 8.6
\end{tabular}
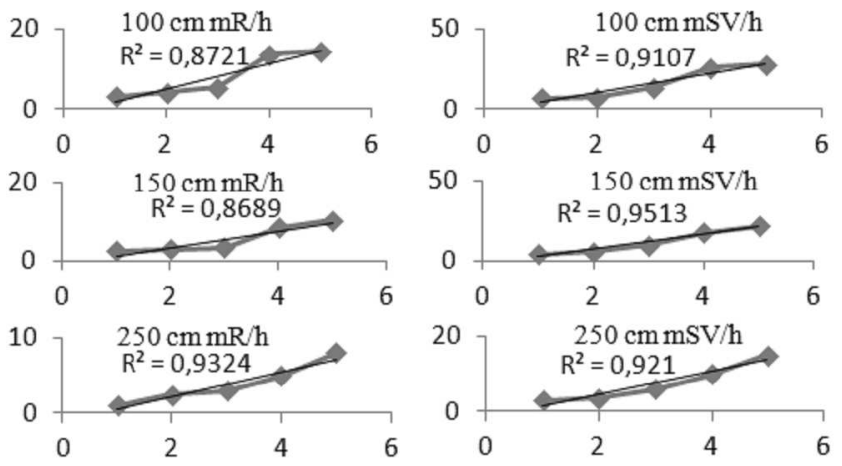

Fig. 2. Percutaneous nephrolithotomy (pnl) graph.

In Figs. 2 and 3, the dosimetric data for different 3 locations including radiation doses changed with distance and X-ray tube locations. The maximum dose found origin and $100 \mathrm{~cm}$ in the end of the works. Distance of $\mathrm{cm}$ from beam central axis were shown that radiation doses decreased with different location of X-ray tube. In Figs. 2 and 3 shown that medical staff have taken a radiation doses with location of X-ray tube. The three different measurements of the dosimeters were all within the permissible range. Other studies have shown the radiation
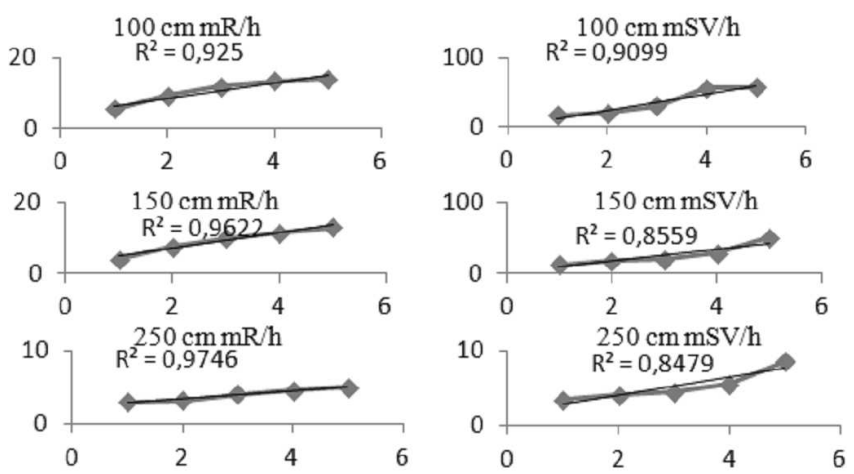

Fig. 3. Lumbar disc herniation (ldh) graph. 
measurements for fluoroscopy-guided intervention pain procedures to be within the permissible range [6-12], but the natural radiation exposure dose in daily life is $2.4 \mathrm{mSv}$.

\section{Discussion}

Continuous fluoroscopy mode routinely used during investigations. For each patient, the average $\mathrm{kV}_{p}$ and $\mathrm{mA}$ values also the average time was measured for each projection. Protective leaden clothing, the leaden thyroid and leaden eye protection to health doctors and personnels was used. As a global average, the natural background radiation is $2.4 \mathrm{mSv}$ per year (UNSCEAR, 2010). In some countries typical background radiation is about $1 \mathrm{mSv}$ per year, and in others it is approximately $3 \mathrm{mSv}$. There are some areas in the world (e.g., India, Brazil, Iran, and France) where the population is exposed to background radiation levels of $5-15 \mathrm{mSv}$ per year. The Commission has recommended a whole body dose limit for workers of $20 \mathrm{mSv}$ per year (averaged over a defined 5 year period; $100 \mathrm{mSv}$ in 5 years) and other limits as in Table II (ICRP, 2007; ICRP 2011a). Even though the annual maximum cumulative dose is $50 \mathrm{mSv}$, wearing protective gear during procedures is highly recommended to reduce the dose of radiation exposure [3]. Obtaining images over several seconds should be avoided when placing a needle. It is better to instead to quickly obtain the images and to save the last image [11]. This way, one can plan the next movement of the needle from the final image and reduce the possible radiation exposure [6]. Also, people who are not needed for the procedure may step outside the procedure room while the image is being observed.

\section{Conclusions}

It must be emphasized that individuals who work with fluoroscopy machines and use the radiation protection tools and methods described in this document, can keep their radiation dose from work with X-rays to less than or around $1 \mathrm{mSv}$ per year and thus there is a role for radiation protection. Working environment for this particular surgery physicians, medical personnel and for personnel: protective clothing, thyroid and protective eyewear made of lead sensitivity must be used. But most of the medical problem, is staff sloppy use of protective clothing and general complaint of personnel seen that is the heavy protective clothing. Especially female doctor, nurses and staff who are often situations that can known or unknown in the operation room. Also in addition to all this, radiology technicians works shooting on fluoroscopy, physicians or health care personnel should be given the necessary training of radiological protection and radiation protection. Although studies to date, physicians, and was pregnancy during on pregnancy are exposed from radiation's bad effects. In addition, the technique of surgery must be well known by the physician and flouroscopy should not be use necessary displaying teams that are exposed to radiation doses below the recommended levels, ICRP the
ALARA "As Low As Reasonably Achievable" principle should not be overlooked.

\section{References}

[1] K.P. Botwin, E.D. Freeman, R.D. Gruber, F.M. Torres Rames, C.G. Bouchlas, J.T. Sanelli, A.F. Hanna, Pain Phys. 4, 343 (2001).

[2] European Commission, 2008. European Guidance on Estimating Population Doses from Medical Ray Procedures, Radiation Protection 154, European Commission, Luxembourg 2008.

[3] S.M. Fishman, H. Smith, A. Meleger, J.A. Seibert, Reg. Anaesth. Pain Med. 27, 296 (2002).

[4] R.A. Geise, T.J. O'Dea, Appl. Radiat. Isotop. 50, 173 (1999).

[5] ICRP, 2007, The 2007 Recommendations of the International Commission on Radiological Protection, ICRP Publication 103, 2007, p. 2.

[6] L. Manchikanti, K.A. Cash, T.L. Moss, V. Pampati, Pain Phys. 5, 385 (2002).

[7] L. Manchikanti, Pain Phys. 7, 465 (2004).

[8] T.B. Shope, Radiographics 16, 1195 (1996).

[9] V. Tse, J. Lising, M. Khadra, Q. Chiam, R. Nugent, L. Yeaman, M. Mulcahy, Aust. NZ J. Surg. 69, 847 (1999).

[10] E. Vano, L. Gonzalez, F. Beneytez, F. Moreno, Br. J. Radiol. 71, 728 (1998).

[11] M. Mahesh, Radiographics 21, 1033 (2001).

[12] Y. Zhou, N. Singh, S. Abdi, J. Wu, J. Crawford, F.A. Furgang, Pain Phys. 8, 49 (2005). 